\title{
COMMENT
}

Received 7 May 2016 | Accepted 9 Aug 2016 | Published 6 Sep 2016

\section{Zika: the cost of neglect}

\author{
Sahotra Sarkar ${ }^{1}$ and Lauren Gardner ${ }^{2}$
}

ABSTRACT The Zika virus is vectored by mosquito species of the genus Aedes, particularly the yellow fever mosquito, Aedes aegypti and, very likely, the Asian tiger mosquito, Ae. albopictus. These species also vector a host of other viral diseases including dengue and chikungunya all of which are "neglected tropical diseases" (NTDs) because of the lack of attention given to them. NTDs are diseases of poverty: They have lacked due attention because they typically affect the poorest populations of the world and at the same time they are not common enough to be profitably exploited by the pharmaceutical industry. We argue that the depth of the current Zika crisis is because of the extent of neglect for NTDs: First, in spite of yellow fever, dengue, chikungunya and other diseases vectored by Aedes mosquitoes, insufficient efforts have been directed towards their population control. Second, specific drugs for combating yellow fever, dengue, or chikungunya do not exist. For the last two, vaccines are yet to be developed (though some trials are finally taking place for one for dengue). Thus the pharmaceutical knowledge base for tackling related viral diseases is lacking. Third, thanks to the neglect even the epidemiological, sociopolitical and economic data required to make credible and timely risk assessments are not available. For instance, in the case of Zika, it would be useful to have a global risk map based on projected travel to and from Brazil for the 2016 Summer Olympics in Rio de Janeiro. Yet, projected travel volumes for chartered flights for the summer of 2016 are not publicly accessible, preventing the creation of credible risk maps. In addition, there is a severe lack of publicly available case data, especially in countries of the South where NTDs have the largest impact. Without reliable and comprehensive outbreak data, risk models necessary for outbreak prediction cannot be validated. Zika has only drawn attention to these problems because of the likelihood of its spread into the affluent North. It is high time that all NTDs are rescued from their dangerous oblivion.

\footnotetext{
${ }^{1}$ Department of Integrative Biology, University of Texas, Austin, Texas, USA 2 School of Civil and Environmental Engineering, UNSW Australia, Sydney, NSW, Australia
} 


\section{Introduction}

uring the last few months of 2015 and 2016, Zika virus disease has emerged as a global public health emergency that has evoked multiple responses from individual and institutional actors across scientific, medical and political establishments. What used to be regarded as a generally mild viral disease is now viewed as a crisis because the newest outbreaks have shown Zika to be linked, probably causally, to a debilitating and once rare foetal condition, microcephaly (Besnard et al., 2014; Besnard et al., 2016; Driggers et al., 2016; Nowakowski et al., 2016; Oliveira Melo et al., 2016; PAHO, 2016a; Schuler-Faccini et al., 2016; Qian et al., 2016; WHO, 2016), besides Guillain-Barré syndrome (GBS), a neurological disorder with immunological origins (Pan American Health Organization/World Health Organization (PAHO), 2016a).

We point out in this comment that the ongoing Zika crisis should not have come as a surprise: While poverty itself plays an aetiological role in many diseases, the rapid explosion of Zika is the price being paid for systemic neglect of a suite of diseases that typically affect the poorest and most disempowered residents of tropical regions. Because of this neglect, not only do we have no tools for the effective treatment and management of Zika virus disease, we have no credible preventive strategies that will significantly reduce the risk of its occurrence. For instance, we cannot even systematically prioritize areas for disease surveillance following the expected increase of travel to and from Brazil in 2016 for the Summer Olympics, and consequent enhanced transport of the disease to other regions of the world.

\section{Neglected tropical diseases (NTDs)}

The suite of diseases that we referred to earlier fall under the rubric of "neglected tropical diseases (NTDs)" in a conceptual framework that emerged after 2000 when the Millennium Development Goals drew attention to "other diseases" besides HIV/AIDS and malaria, especially in the global South (Hotez, 2013). Originally, the NTDs were presumed to consist of seven major (and 13 total) diseases, including three soil-transmitted helminth infections (ascariasis, trichuriasis and hookworm infection), schistosomiasis, lymphatic filariasis, onchocersiasis and trachoma. That set has been extended to over 17 since 2010 (Hotez, 2013). Dengue has been recognized as a member of this group at least since 2006 (Hotez and Ferris, 2006). More recently, chikungunya fever has been accorded paradigmatic status as an NTD that is emerging as a major global public health problem (Rougeron et al., 2015). Dengue and chikungunya are caused by flaviviruses that are so closely related that they are believed to have switched names during the last century (Halstead, 2015).

This neglect comes in different forms and is due to three factors (Hotez, 2008): (1) each of these diseases affects a relatively small subpopulation even though the total population affected is comparable to the major tropical diseases mentioned above; (2) as indicated earlier, the subpopulations affected are often the most marginalized ones even in their own national contexts; and (3) by and large, these diseases have low mortality even though they have high morbity. Because of these factors NTDs have low priority for policymakers and insufficient visibility to attract the attention of the large non-governmental organizations that have come to dominate funding for public health in the global South, particularly in response to malaria. The pharmaceutical industry has largely ignored these diseases because of low expected profit returns from marginal communities which have limited buying power and, sometimes, low population size.

Only when NTDs emerge as problems in the North-as is increasingly occurring, for instance, with Chagas disease in Texas (Sarkar et al., 2010; Garcia et al., 2015) - do they receive due attention. As Zika shows, diseases do not respect boundaries, neither national boundaries nor the economic boundaries that divide the South from the North. However, only when they cross from the South to the North do they get resources devoted to their control, often again only with a focus on the North. For instance, there has just been a surge of resources dedicated to Zika in the United States because an autochthonous Zika cycle is now believed to have been established in Florida (Mohny, 2016).

Below we note some of the most salient features of the emergence and spread of Zika. Then we note four facets of our unpreparedness for its emergence, that is, the forms of neglect, and in each case we emphasize the extent to which this facet of neglect was corrigible had due diligence been exercised when the emergence of Zika was first noticed.

\section{Aedes mosquitoes and infectious disease}

The two diseases mentioned earlier, dengue and chikungunya, are relevant to the Zika crisis because it, too, is caused by a flavivirus that is very closely related to the other two (Peterson et al., 2016). More importantly, all three diseases are propagated by mosquito vectors from the genus Aedes with a single species Ae. aegypti being the dominant vector in each case. This means that if the spread of dengue or chikungunya had been curtailed by the control of these vectors and exposure to their bites, we probably would not have faced a Zika crisis close to the level at which it is occurring today. There should have been adequate time: Ae. aegypti was recognized as the primary vector for dengue as early as 1906, one of the first insect-borne diseases to be so recognized (Spielman and D'Antonio, 2002). Instead dengue has emerged as the most rapidly spreading vector-borne disease in the world during the last decade (Gardner and Sarkar, 2013). Ae. aegypti is also the primary vector for yet another, often fatal, flaviviral disease, yellow fever, that was a major public health problem in the United States in the nineteenth century (Murphy, 2014). If any single vector species should long have been globally prioritized for control, this was the obvious choice. With the disappearance of yellow fever from the global North, no such action was taken.

\section{Spread of the Zika virus}

Knowledge of the existence of the Zika virus and of the potential for human disease cases is not new. The virus was first isolated in 1947 in a sentinel macaque in the Zika forest of Uganda (Kirya and Okia, 1977), and it was first found in humans in 1952 (Dick, 1952). Until 2007 reported Zika outbreaks were limited to small isolated epidemics in equatorial Africa and tropical Asia, with only 14 documented human cases (Duffy et al., 2009). However, since the first documented recent outbreak in 2007, the number of Zika cases has increased exponentially with each reported outbreak.

The 2007 outbreak of Zika occurred on Yap Island in the Federated States of Micronesia in the North Pacific, with less than 200 acknowledged cases (Duffy et al., 2009). In 2013 an outbreak occurred in French Polynesia, with around 28,000 suspected cases (Ioos et al., 2014), after which Zika began to be generally recognized as a re-emerging infectious disease. The 2013 outbreak subsequently spread from French Polynesia to other Pacific Islands including New Caledonia, Cook Island and Easter Island, in which autochthonous transmission occurred (Waehre et al., 2013). The virus has since continued its spread eastwards, from Africa through Asia and the Pacific, and into the Americas (Lanciotti et al., 2008; Lanciotti et al., 2015). Phylogenetic analyses of virus RNA sequences suggest Zika was first introduced into the Americas between May and December 2013 (Faria et al., 
2016), 2 years prior to the start of the most recent and largest outbreak of Zika ever reported.

The current Zika virus outbreak originated in Brazil in May 2015 (Hennessey et al., 2016), and by May 2016 more than 35 countries and territories in Latin America and the Caribbean had reported local transmission, with over a million estimated cases (Pan American Health Organization/World Health Organization (PAHO), 2016a). Travel-imported cases have also been reported throughout Europe, Asia, and the Middle East, as well as the United States, Australia and New Zealand (Nah et al., 2016), representing the first time Zika has been reported in many of these countries. In late July 2016, an autochthonous Zika cycle was reported to have been established in the United States, in Florida in the Miami region (Mohny, 2016), in concordance with a risk analysis that we had published earlier (Gardner et al., 2016). The unprecedented size of the outbreak, rate of spread and potential links with microcephaly and GBS have prompted the World Health Organization (WHO) to declare the current Zika virus outbreak a public health emergency of international concern (WHO, 2016b).

\section{Four forms of neglect}

No tools for treatment. Zika was not previously considered a major public health threat because its symptoms were relatively mild, and nearly $80 \%$ of those infected report no symptoms at all (Duffy et al., 2009). The seemingly mild nature of the disease coupled with the geographically limited extent of affected regions, all in the global South, resulted in traditionally limited resources for research aimed at designing specific responses to disease cases, that is, to its management or cure.

But, as we noted earlier, a Zika outbreak in French Polynesian 2013 led to 28,000 cases. A link between Zika and GBS was noticed subsequently and has since been reviewed (Cauchemez et al., 2016; Cao-Lormeau et al., 2016). Yet, no effort seems to have been directed towards a concerted strategy for disease management. Moreover, a retrospective study now shows that a link with microcephaly could have been found had Zika cases been carefully followed (Oehler et al., 2014). It is likely that the recognition of such a link would have led to the availability for disease-specific tools for treatment and management today. Neglect has put us in a situation where we have no tools for Zika treatment.

Problems of detection. This neglect also helps explain why detection of the virus is unusually resource-intensive (Waggoner and Pinsky, 2016). Antibody-based tests often cannot distinguish between Zika and related viruses. Tests based on antigens do not exist for Zika (unlike, for instance, the case of dengue). Point-ofcare tests are not yet available, and went under development only after the crisis erupted (Waggoner and Pinsky, 2016). To make matters worse, this unpreparedness is coupled with an inherent diagnostic challenge associated with Zika because of the overlap in symptoms and close antigenic relationships between it and many other arboviruses that often co-circulate (dengue, West Nile and yellow fever, possibly with unidentified or poorly characterized flaviviruses), further increasing the likelihood of frequent misdiagnoses. The most reliable diagnostic tests are based on RNA, but commercial tests, including one developed by Altona Diagnostics (Hamburg, Germany), are just becoming available, and clinical efficacy is yet to be evaluated intensively (Waggoner and Pinsky, 2016). The Federal Drugs Administration in the United States has recently authorized a test from Quest Diagnostics (2016) for emergency use, but it also remains to be evaluated.
No tools for prevention. In the absence of treatment for Zikaand its associated complications-the critical epidemiological response to the disease must be its prevention. For diseases with insect vectors, the obvious response is the control of that vector. For all infectious diseases, vaccine development is important. Neither has been adequate for Zika.

Failure of vector control. Traditional methods of vector control consist of the use of insecticides, larvicides and destruction of larval breeding sites. Insecticides and larvicides, even when they have been systematically used (for instance, in Brazil), have been used at such low volumes that they have been ineffective (Yakob and Walker, 2016). However, widespread insecticide resistance (Lima et al., 2011), similar to what was seen in attempts at malaria vector control, befuddles this strategy. Moreover, it is impractical to attempt to destroy all breeding sites (pools or even containers of water) at a regional level in wet tropical or subtropical regions. Attention has, therefore, shifted to the use of three novel approaches: (1) RIDL (the Release of Insects carrying Dominant Lethal genes) (Phuc et al., 2007); (2) Wolbachia infections, which works for at least Ae. aegypti (Iturbe-Ormaetxe et al., 2011); and (3) gene drives (Adelman and Tu, 2016). The first two of these methods have been available for several years, and because of the continuing spread of dengue, have even been field-tested (Carvalho et al., 2015). Yet, because of lack of attention to NTDs, they have not been readied to the extent required to respond to the Zika crisis.

Failure of vaccine research investment. In spite of Zika becoming a major threat since 2007, efforts at the development of vaccines for Zika were non-existent until the present crisis. We are now assured that a vaccine may be available within a year. Twentyeight thousand cases of Zika in French Polynesia in 2013 were not enough to spur Zika vaccine development. Had they been, and if the presently suggested timeline of vaccine development within a year or so is credible, then there should have been a vaccine available now.

\section{Poor data for risk assessment}

Absent vector competence data. Accurate risk assessment of any vector-borne disease requires quantitative estimates of the vector efficiency of each vector species (Moffett et al., 2007). For Zika, that $A$ e. aegypti is a vector is well-established. Many studies have implicated Ae. albopictus as a potential vector in Africa and Asia (Wong et al., 2013; Grard et al., 2014). However, until very recently no attempt had been made to quantify the relative vector efficiency of these species. This ratio is critical to determining the risk from Zika, specifically whether autochthonous disease transmission will be confined to the tropics and neighbouring part of the subtropics or whether it can spread to most of the temperate regions of the world (Gardner et al., 2016). Moreover, the virus has been collected from many mosquito species, including those from the genera, Anopheles, Culex and Mansonia besides at least eight other Aedes species. Whether these species can transmit Zika is unknown (Ayres, 2016). All these data should have been collected at least immediately after the first major outbreak in 2007 that we discussed earlier. Only recently, one analysis compared the vector efficiency of Ae. aegypti and Ae. albopictus from a very limited set of regions (Chouin-Carneiro et al., 2016). Though it concluded that the two species were roughly equally competent, it found large differences within the species, and, in general, very low efficiency in all cases. The study raises more questions than it answers, again highlighting what should have been studied starting in 2007. 
Absent case data. For disease outbreaks, the quality and availability of case data are often strongly correlated with a region's economic status. As such, regions in the South that harbour most NTDs are at a disadvantage when it comes to risk mitigation and planning. Even for countries with available public health resources, Zika surveillance and accurate diagnoses pose a significant challenge. Part of the challenge is due to the problem of detection that was discussed earlier. As such, many Zika cases have gone undetected and continue to do so because of the high fraction of asymptomatic cases, coupled with the typically high burden of dengue in several regions such as Brazil from which the current crisis is spreading. This situation has probably led to frequent misidentification of Zika cases as those of dengue.

Beyond detection issues, efforts to collect and share Zika case data have been inadequate, and at present, publicly available Zika case data is limited and highly region specific. This limitation significantly restricts the set of risk assessment models that can be implemented, as well as the reliability of any projected risk estimates. For example, a recent study aimed at predicting the potential exposure to Zika virus for foreign tourists during the 2016 Olympic Games in Rio de Janeiro (Burattini et al., 2016) relied on 2008 dengue outbreak data because data on the current Zika outbreak are unavailable. In efforts to address this issue, WHO has provided interim guidelines on surveillance methods (WHO, 2016c) and laboratory testing (WHO, 2016d), and there are multiple ongoing efforts to make research open access and available in real time (Global Health Network, 2016; Kallas and O'Connor, 2016; Kmietowicz, 2016; PAHO, 2016b). However, these efforts are long overdue.

Poor travel data. Human mobility is well-established as the major underlying mechanism responsible for the global spread of Zika (Bogoch et al., 2016; Gardner et al., 2016). We will only focus on global air travel because of its relevance to Zika, although data on regional movements using alternative travel modes such as road and rail are also critical to modelling disease spread in general, and pose an equal or greater challenge to acquire. Air travel data are necessary to predict to where and when Zika will spread. However, the air travel data that are publicly available are insufficient for this purpose. For example, of the previous studies that relied on publicly available air travel data to map the potential spread of Zika into new regions, one data set was global but aggregated to the country level (Nah et al., 2016), while another, though disaggregated to the airport level, was limited to travel out of the United States (Monaghan et al., 2016). In both studies, travel volumes were only available for individual flight legs (as opposed to complete travel journeys), resulting in overestimates of risk at cities with major airport hubs, and underestimates of risk at the actual destination cities. Global-level data sets capturing complete and highly disaggregated passenger travel itineraries are available from organizations such as International Air Traffic Association and OAG (Air Travel Intelligence), and have been used to study the spreading risk posed by Zika (Bogoch et al., 2016; Gardner et al., 2016) among other diseases, however, these data sets are expensive, historical and still coarsely temporally aggregated (monthly travel volume is the most disaggregated level of data available). In order for public health authorities to plan and prepare for the impact of global events such as the 2016 summer Olympics in Rio, a centre of the current Zika virus outbreak, disaggregated projected travel data is necessary. While OAG and IATA have access to forward schedules data that are filed by airlines directly, the database only captures commercial airlines ticketed bookings. A large proportion of air travel to special events utilizes general aviation (for example, private charter flights), which are not required to file their schedules information with the civil authority. Furthermore, there is no consensus of the general aviation coverage of the world total air travel; hence even the data available for purchase gives an incomplete picture of the future demand.

\section{Conclusions}

The problems we have noted in our preparedness to respond to the Zika crisis is the price we pay for ignoring NTDs until they pose a serious crisis for the North. If there had been due attention to dengue, which has been recognized as a severe problem in tropical countries for over a century, the innovative vector control methods mentioned earlier that are just now being tested could probably have curtailed Aedes populations during the last decade. At the very least, the emergence of Chikungunya should have spurred those efforts more than a decade ago. Instead we are faced with a highly uncertain future with regard to Zika, and a large number of unanswered questions, which are only now receiving attention. Perhaps, first and foremost, the question of a causal link between Zika and microcephaly has been potentially debatable until very recently (Rasmussen et al., 2016), but should have been detected much earlier. What we do not know: if a causal link does exist, how big is the risk? The situation is the same with respect to Zika and GBS. Then there is the question of the relative importance of sexual transmission in the spread of Zika. Once again, if Zika data collection and reporting had been prioritized before now, we could have been better prepared for these seemingly new clinical manifestations that have marked the ongoing Zika outbreak. For instance, the 2013-2014 Zika outbreak in French Polynesia might have revealed the linkage between microcephaly and Zika years earlier.

There is also significant uncertainty underlying the risk of global spread and establishment of Zika. A portion of this uncertainty is because of the uncertainty about the phenology and ecology of the vector species that we noted earlier. If the vector competence were better understood, and reliable spatial-temporal case data and travel data were publicly available, a proper risk assessment could have been conducted at the onset of the current outbreak, and appropriate efforts could have been put in place to better contain its spread. Likewise, the 2016 summer Olympics in Rio de Janeiro poses potentially significant harm; however, due to the limitations on available data mentioned previously, this risk cannot be quantified and mapped spatially. Projected travel data, as well as a global database of reported Zika cases is minimally necessary to properly assess global risk of spread of the disease.

Additional ongoing research efforts must seek to answer the following questions about Zika: Why is the latest outbreak so much larger than past outbreaks in Africa and the Asia-Pacific region? Has the virus mutated to become more contagious? Or is it only that the quality of reporting is better? And given the varying levels of reporting and high rate of asymptomatic cases, how big is the actual outbreak in Latin America? Can asymptomatic individuals efficiently spread the virus? This is particularly relevant for the risk of spread to new regions. Lastly, how does previous exposure and possible immunity to related viruses like Dengue and Chikungunya impact the risk associated with Zika infection? These questions highlight just some of the uncertainties surrounding Zika that should already have at least had tentative answers. If Zika does indeed become anything close to the global crisis that $\mathrm{WHO}, \mathrm{PAHO}$ and $\mathrm{CDC}$ now fear, it will only be our fault.

\section{References}

Adelman ZN and Tu Z (2016) Control of mosquito-borne infectious diseases: Sex and gene drive. Trends in Parasitology; 32 (3): 219-229.

Ayres CFJ (2016) Identification of Zika virus vectors and implications for control. The Lancet Infectious Diseases; 16 (3): 278-279. 
Burattini MN et al (2016) Potential exposure to Zika virus for foreign tourists during the 2016 Carnival and Olympic games in Rio de Janeiro, Brazil. Epidemiology and Infection; 144 (9): 1904-1906.

Besnard $\mathrm{M}$ et al (2016) Congenital cerebral malformations and dysfunction in fetuses and newborns following the 2013 to 2014 Zika virus epidemic in French Polynesia. Euro Surveillance; 21 (13): pii-30181.

Besnard M, Lastere S, Teissier A, Cao-Lormeau V and Musso D (2014) Evidence of perinatal transmission of Zika virus, French Polynesia, December 2013 and February 2014. Euro Surveillance; 19 (13): pii-20751.

Bogoch II et al (2016) Anticipating the international spread of Zika virus from Brazil. The Lancet; 387 (10016): 335-336.

Cao-Lormeau VM et al (2016) Guillain-Barré syndrome outbreak associated with Zika virus infection in French Polynesia: A case-control study. The Lancet; 387 (10027): 1531-1539.

Carvalho DO et al (2015) Suppression of a field population of Aedes aegypti in Brazil by sustained release of transgenic male mosquitoes. PLoS Neglected Tropical Disease; 9 (7): e0003864

Cauchemez S et al (2016) Association between Zika virus and microcephaly in French Polynesia, 2013-15: A retrospective study. The Lancet; 387 (10033): 2125-2132.

Chouin-Carneiro T et al (2016) Differential susceptibilities of Aedes aegypti and Aedes albopictus from the Americas to Zika virus. PLoS Neglected Tropical Disease; 10 (3): e0004543.

Dick GWA (1952) Zika virus (II). Pathogenicity and physical properties. Transactions of the Royal Society of Tropical Medicine and Hygiene; 46 (5): 521-534.

Driggers RW, Ho CY, Korhonen EM, Kuivanen S et al (2016) Zika virus infection with prolonged maternal viremia and fetal brain abnormalities. New England Journal of Medicine; 374: 2142-2151.

Duffy MR et al (2009) Zika virus outbreak on Yap Island, federated states of Micronesia. New England Journal of Medicine; 360 (24): 2536-2543.

Faria NR et al (2016) Zika virus in the Americas: Early epidemiological and genetic findings. Science; 352 (6283): 345-349.

Garcia MN, Woc-Colburn L, Aguilar D, Hotez PJ and Murray KO (2015) Historical perspectives on the epidemiology of human Chagas disease in Texas and recommendations for enhanced understanding of clinical Chagas disease in the Southern United States. PLOS Neglected Tropical Disease; 9 (11): e0003981.

Gardner L, Chen N and Sarkar S (2016) Global risk of Zika virus depends critically on vector status of Aedes albopictus [Letter]. Lancet Infectious Diseases; 16 (5): $522-523$.

Gardner L and Sarkar S (2013) A global airport-based risk model for the spread of dengue infection via the air transport network. PLoS ONE; 8 (8): e72129.

Global Health Network. (2016) Zika Infection, https://zikainfection.tghn.org/, accessed 8 August 2016.

Grard G et al (2014) Zika virus in Gabon (Central Africa)-2007: A new threat from Aedes albopictus? PLoS Neglected Tropical Diseases; 8 (2): e2681.

Halstead SB (2015) Reappearance of chikungunya, formerly called dengue, in the Americas. Emerging Infectious Diseases; 21 (4): 557-561.

Hennessey M, Fischer M and Staples JE (2016) Zika virus spreads to new areasregion of the Americas, May 2015-January. Morbidity and Mortality Weekly Rep; 65 (3): 55-58.

Hotez PJ (2013) NTDs V. 2.0: "Blue marble health"-neglected tropical disease control and elimination in a shifting health policy landscape. PLoS Neglected Tropical Disease; 7 (11): e2570.

Hotez PJ (2008) Forgotten People, Forgotten Diseases: The Neglected Tropical Diseases and their Impact on Global Health and Development. ASM Press: Washington DC.

Hotez PJ and Ferris MT (2006) The antipoverty vaccines. Vaccine; 24 (31): 5787-5799.

Ioos S, Mallet HP, Leparc Goffart I, Gauthier V, Cardoso T and Herida M (2014) Current Zika virus epidemiology and recent epidemics. Medecine et Maladies Infectieuses; 44 (7): 302-307.

Iturbe-Ormaetxe I, Walker T and LO'Neill S (2011) Wolbachia and the biological control of mosquito-borne disease. EMBO reports; 12 (6): 508-518.

Kallas EG and O'Connor DH (2016) Real-time sharing of Zika virus data in an interconnected world. JAMA Pediatrics; 170 (7): 633-634.

Kirya BG and Okia NO (1977) A yellow fever epizootic in Zika forest, Uganda, during 1972: Part 2: Monkey serology. Transactions of Royal Society of Tropical Medicine Hygiene; 71 (4): 300-303.

Kmietowicz Z (2016) Research bodies vow to share data on Zika. BMJ; 352, i877. Lanciotti RS et al (2008) Genetic and serologic properties of Zika virus associated with an epidemic, Yap state, Micronesia, 2007. Emerging Infectious Diseases; 14 (8): 1232-1239.

Lanciotti RS, Lambert AJ, Holodniy M, Saavedra S and del Carmen Castillo Signor L (2015) Phylogeny of Zika virus in Western Hemisphere. Emerging Infectious Diseases; 22 (5).

Lima EP et al (2011) Insecticide resistance in Aedes aegypti populations from Ceará, Brazil. Parasites \& Vectors; 4 (5): 2-12.
Moffett A, Shackelford N and Sarkar S (2007) Malaria in Africa: Vector species' niche models and relative risk maps. PLoS One; 2 (9): e824.

Mohny G (2016) 10 Additional Zika Cases found in Florida outbreak: Governor activates emergency response. $A B C$ News. 01 August, http://abcnews.go.com/ Health/10-additional-zika-cases-found-florida-outbreak-governor/story?id = 41043116, accessed 8 August 2016.

Monaghan AJ et al (2016) On the seasonal occurrence and abundance of the Zika virus vector mosquito Aedes Aegypti in the contiguous United States. PLOS Currents Outbreaks; online publication 16 March, http://currents.plos.org/ outbreaks/article/on-the-seasonal-occurrence-and-abundance-of-the-zikavirus-vector-mosquito-aedes-aegypti-in-the-contiguous-united-states/.

Murphy J (2014) An American Plague: The True and Terrifying Story of the Yellow Fever Epidemic of 1793. Houghton Mifflin Harcourt: New York, NY.

Nah K, Mizumoto K, Miyamatsu Y, Yasuda Y, Kinoshita R and Nishiura H (2016) Estimating risks of importation and local transmission of Zika virus infection PeerI; 4 (e1904).

Nowakowski TJ, Pollen AA, Di Lullo E, Sandoval-Espinosa C, Bershteyn M and Kriegstein AR (2016) Expression analysis highlights AXL as a candidate Zika virus entry receptor in neural stem cells. Cell Stem Cell; 18 (5): 591-596.

Oehler E et al (2014) Zika virus infection complicated by Guillain-Barré syndromecase report, French Polynesia, December 2013. Euro Surveillance; 19 (9): pii-20720.

Oliveira Melo AS, Malinger G, Ximenes R, Szejnfeld PO, Alves Sampaio S and Bispo De Filippis AM (2016) Zika virus intrauterine infection causes fetal brain abnormality and microcephaly: Tip of the iceberg? Ultrasound in Obstetrics and Gynecology; 47 (1): 6-7.

Pan American Health Organization/World Health Organization. (2016a) Zika epidemiological update, 21 April. Washington, D.C.

Pan American Health Organization/World Health Organization. (2016b) Zika Research Projects List. http://www2.paho.org/zika-research/, accessed 8 August 2016.

Petersen LR, Jamieson DJ, Powers AM and Honein MA (2016) Zika virus. New England Journal of Medicine; 374: 1552-1563.

Phuc HK et al (2007) Late-acting dominant lethal genetic systems and mosquito control. BMC biology; 5 (1): 11.

Qian X et al (2016) Brain-region-specific organoids using mini-bioreactors for modeling ZIKV exposure. Cell; 165 (5): 1238-1254.

Quest Diagnostics. (2016) Zika test from Quest Diagnostics authorized by the FDA for emergency use. http://newsroom.questdiagnostics.com/2016-04-28-ZikaTest-from-Quest-Diagnostics-Authorized-by-the-FDA-for-Emergency-Use, accessed 8 August 2016.

Rasmussen SA, Jamieson DJ, Honein MA and Petersen LR (2016) Zika virus and birth defects-reviewing the evidence for causality. New England Journal of Medicine; 374: 1981-1987.

Rougeron V, Sam IC, Caron M, Nkoghe D, Leroy E and Roques P (2015) Chikungunya, a paradigm of neglected tropical disease that emerged to be a new health global risk. Journal of clinical Virology; 64, 144-152.

Sarkar S, Strutz SE, Frank DM, Rivaldi CL, Sissel B and Sanchez-Cordero V (2010) Chagas disease risk in Texas. PLoS Neglected Tropical Disease; 4 (10): e836.

Schuler-Faccini L et al (2016) Possible association between Zika virus infection and microcephaly-Brazil, 2015. Morbidity Mortality Weekly Report; 65 (3): 59-62.

Spielman A and d'Antonio M (2002) Mosquito: The Story of Man's Deadliest Foe. Hyperion: New York.

Waehre T, Maagard A, Tappe D, Cadar D and Schmidt-Chanasit J (2013) Zika virus infection after travel to Tahiti, December 2013 [Letter]. Emerging Infectious Disease; 20 (8), 1412-1414.

Waggoner JJ and Pinsky BA (2016) Zika virus: Diagnostics for an emerging pandemic threat. Journal of clinical microbiology; 54 (4): 860-867.

Wong PS, Li MZ, Chong CS, Ng LC and Tan CH (2013) Aedes (Stegomyia) albopictus (Skuse): a potential vector of Zika virus in Singapore. PLoS Negl Trop Dis; (8): e2348.

World Health Organization. (2016a) WHO situation report: Zika Virus, microcephaly and Guillain-Barre syndrome [Web Page], http://apps.who.int/ iris/bitstream/10665/204961/1/zikasitrep_7Apr2016_eng.pdf?ua =1, accessed 8 August 2016.

World Health Organization. (2016b) WHO statement on the first meeting of the International Health Regulations (2005) (IHR 2005) Emergency Committee on Zika virus and observed increase in neurological disorders and neonatal malformations, http://www.who.int/mediacentre/news/statements/2016/zikathird-ec/en/, accessed 17 August 2016.

World Health Organization. (2016c) Surveillance for Zika virus infection, microcephaly and Guillain-Barré syndrome: Interim guidance. http://www who.int/csr/resources/publications/zika/surveillance/en/, accessed 17 August 2016.

World Health Organization. (2016d) Laboratory testing for Zika virus infection: Interim guidance. http://www.who.int/csr/resources/publications/zika/labora tory-testing/en/.

Yakob L and Walker T (2016) Zika virus outbreak in the Americas: The need for novel mosquito control methods. The Lancet Global Health; 4 (3): e148-e149. 


\section{Additional information}

Competing interests: The authors declare no competing financial interests.

Reprints and permission information is available at http://www.palgrave-journals.com/ pal/authors/rights_and_permissions.html

How to cite this article: Sarkar S and Gardner L (2016) Zika: the cost of neglect. Palgrave Communications. 2:16060 doi: 10.1057/palcomms.2016.60. (c) (i) This work is licensed under a Creative Commons Attribution 4.0 cc) International License. The images or other third party material in this article are included in the article's Creative Commons license, unless indicated ?otherwise in the credit line; if the material is not included under the Creative Commons license, users will need to obtain permission from the license holder to reproduce the material. To view a copy of this license, visit http://creativecommons.org/ licenses/by/4.0/ 